\section{Carbon monoxide residues in vacuum-packed yellowfin tuna loins (Thunnus Albacares)}

\author{
Raffaele Marrone, ${ }^{1}$ Celestina Mascolo, ${ }^{1}$ \\ Giuseppe Palma, ${ }^{2}$ Giorgio Smaldone, ${ }^{1}$ \\ Mariagrazia Girasole, ${ }^{1}$ Aniello Anastasio ${ }^{1}$ \\ 'Department of Veterinary Medicine and \\ Animal Production, University of Naples \\ Federico II; ${ }^{2}$ National Association of \\ Processing Fish Industries, Rome, Italy
}

\begin{abstract}
The use of carbon monoxide (CO) in fresh fish has generated considerable debate. Carbon monoxide is used to treat fresh fish in order to retain its fresh red appearance for a longer period. It reacts with the oxy-myoglobin to form a fairly stable cherry red carboxy-myoglobin complex that may mask spoilage, because the $\mathrm{CO}$-complex can be stable beyond the microbiological shelf life of the meat. The presence of $\mathrm{CO}$ in tuna fish (Thunnus Albacares) has been investigated by means of optical spectroscopy. Formation of the $\mathrm{CO}$ adduct can be easily detected by the combined analysis of electronic absorption spectra in their normal and second derivative modes, monitoring the intense Soret band at $420 \mathrm{~nm}$. Samples were judged as $\mathrm{CO}$ treated when their levels were higher than $200 \mathrm{ng} / \mathrm{g}$. Only two positive samples out of 29 analyzed were detected. The high level of uncertainty $(0.30)$ of the method requires the use of more specific and sensitive methods for confirmatory analysis.
\end{abstract}

\section{Introduction}

The seafood industry is continuously attempting to develop new technologies aimed at extending the shelf life of fish products, without changing their nutritional and sensory characteristics. The freshness of tuna meat is generally judged by its bright red colour. The desirable colour is due to the level of oxygenated myoglobin, which is present in the red muscle fibres. In order to retain its fresh red colour for a longer period, carbon monoxide ( $\mathrm{CO}$ ) gas has been used to treat meat in the modified atmosphere packaging (MAP) system. The carbon monoxide reacts with the oxy-myoglobin to form a very stable carboxy-myoglobin complex (CO-Mb) as the partition coefficient for $\mathrm{CO}$ is about 50 -fold higher than that of oxygen (Antonini and Brunori, 1971). There are no direct health implications from eating $\mathrm{CO}$ treated tuna. However, $\mathrm{CO}$ may mask spoilage, because the stable cherry red colour can last beyond the microbiological shelf life of the meat. In this respect, it has to be considered that tuna fish, like other Scombroid fish, is commonly associated with cases and outbreaks of histamine intoxication. CO-treatment of fish and meat is allowed at industrial level in the United States and in the Netherlands (Schubring, 2008), but is not permitted in the European Community. In fact, CO is not included in the list of allowed food additives (EU Directive 95/2/EC; European Commission, 1995). Recently, frozen yellowfin tuna loins (Thunnus Albacares) with the characteristic cherry red colour typical of the treatment with $\mathrm{CO}$, have been introduced into the EU market. In accordance to the EU Regulation No 178/2002 (European Commission, 2002) a rapid alert system has been notified on these products. Different methods are available for the analysis of $\mathrm{CO}$ in food, useful for forensic purposes, including spectrophotometric methods (Bylkas and Andersson, 1997; Cruz et al., 1993; Sano and Hashimoto, 1958; Watts et al., 1978). Aim of this work was the research of the presence and concentration of $\mathrm{CO}$ in tuna fish loins (Thunnus Albacares) with a spectrophotometric method.

\section{Materials and Methods}

From October to December 2013, twentynine tuna loins of Thunnus Albacares coming from eight batches and individually vacuum packaged were examined. The samples were sampled randomly from the distribution establishment and immediately transported under conditions of constant temperature $\left(0-4^{\circ} \mathrm{C}\right)$ to the laboratory of the Food Inspection Section of the Department of Veterinary Medicine and Animal Productions in Naples, where the label data (lot, capture date, freezing and thawing time, vacuum and capture time) were verified and recorded. Three parts of about $10 \mathrm{~g}$ from the dorsal, ventral and lateral parts of the each loin were singly analyzed for the qualitative and quantitative determination of carbon monoxide using UV-VIS spectrophotometry (Stonek et al., 2004; Smulevich et al., 2007). The relative expanded uncertainty from the validation data was found to be equal to 0.30 . The results obtained from the average of three determinations are expressed in $\mathrm{ng} / \mathrm{g}$ of carbon monoxide.

\section{Results}

The $\mathrm{C} 0$ content in 27 out of 29 examined loins was found to be less than $200 \mathrm{ng} / \mathrm{g}$, a value that is considered the internationally
Correspondence: Raffaele Marrone, Department of Veterinary Medicine and Animal Production, University of Naples Federico II, Via Federico Delpino 1, 80137 Naples, Italy .

Tel: +39.081.2536464 - Fax: +39.081.458683.

E-mail: raffaele.marrone@uinna.it

Key words: Carbon monoxide; Tuna fish; Thunnus Albacares; Shelf life; Spectrophotometric method.

Conflict of interest: the authors declare no potential conflict of interest.

Received for publication: 9 July 2014.

Revision received: 22 December 2014.

Accepted for publication: 27 December 2014.

This work is licensed under a Creative Commons Attribution 3.0 License (by-nc 3.0).

(C) Copyright R. Marrone et al., 2015 Licensee PAGEPress, Italy

Italian Journal of Food Safety 2015; 4:4528

doi:10.4081/ijfs.2015.4528

accepted limit for a physiological CO content in muscle tissues (Ministry of Health and Welfare of Japan, 1995). Results indicated only two positive samples out of 29 analyzed when the average value of the three parts of each loin were considered. In F2 loin, sampled on $23 / 10 / 13$, an average value of $777 \mathrm{ng} / \mathrm{g}$ of $\mathrm{CO}$ was found (Table 1). In F4 loin, sampled on $29 / 10 / 13$, the CO concentration was higher than the natural limit within the margin of uncertainty provided by the method used. On the whole out of the eighty-seven analyzed samples (Fa dorsal; Fb lateral and Fc ventral parts of each loin) only twelve samples (equally distributed between the dorsal and ventral parts) showed values higher than $200 \mathrm{ng} / \mathrm{g}$ (Table 2).

\section{Discussion}

Since 2003, EU Commission has notified to all member countries through the Rapid Alert System for Food and Feed (RASFF) the presence of carbon monoxide in tuna (Thunnus Albacares) from South-East Asian countries (FAO Area 71 and 57) and from some Member States. According to many authors, very low concentrations of carbon monoxide $(0.3-0.5 \%)$ are necessary in the atmosphere for the formation of the $\mathrm{CO}$ hemoglobin in food. When this gas increases $(0.1-0.5 \%)$ the reduction of deoxy-myoglobin is favored and the browning of meat is tempered. Carbon monoxide is not included in the positive list of food additives of EU Regulation N.o 1333/2008 (European Commission, 2008). In the treated product, the 
colour may mask the deterioration associated with potential risk of scombroid syndrome. Therefore CO treatment is not allowed within the EU with the exception of the Netherlands where the treatment (cold smoking method clear smoke ${ }^{\circledR}$ ) is accepted, restricting the marketing of the processed products to the national territory. Today, in different parts of the world (USA, Japan, Southeast Asia), the seafood industry requires the approval of the treatment with carbon monoxide based on the absence of toxicity of the compound. For the Food and Drug Administration (USA) the tuna is wrongly labelled if it is treated with carbon monoxide but the presence of the additive in the label is not declared. Obviously, the target is to determine the minimal $\mathrm{CO}$ dose to obtain the desired colour.

\section{Conclusions}

Results from the present research showed only two positive samples out of 29 analyzed ( $3 / 3$ rates). In some aliquots of the negative samples concentrations near limit of $200 \mathrm{ng} / \mathrm{g}$ were observed and this results show the high variability in $\mathrm{CO}$ distribution. The significant margin of uncertainty $(0.30)$ of the spectrophotometric method requires the adoption of more specific and sensitive methods. The

Table 1. Carbon monoxide content and uncertainty in tuna loins analyzed in first step (October-November 2013).

\begin{tabular}{lcccc} 
Sample & Sample weight $(\mathrm{g})$ & Cco $(\mathrm{ng} / \mathrm{g})$ & U $(\mathrm{ng} / \mathrm{g})$ & Result \\
F1 (dorsal) & 10.09 & 188.20 & 56.50 & Negative \\
F1 (lateral) & 10.01 & 24.20 & 7.30 & Negative \\
F1 (ventral) & 10.01 & 252.60 & 75.80 & Negative \\
Mean & & 155.00 & 46.50 & \\
F2 (dorsal) & 10.00 & 746.10 & 223.80 & Positive \\
F2 (lateral) & 10.10 & 787.60 & 236.30 & Positive \\
F2 (ventral) & 9.80 & 797.40 & 239.20 & Positive \\
Mean & & 777.00 & 233.10 & \\
\hline F3 (dorsal) & 10.50 & 266.00 & 79.80 & Negative \\
F3 (lateral) & 10.10 & 163.30 & 49.00 & Negative \\
F3 (ventral) & 10.10 & 25.80 & 7.70 & Negative \\
Mean & & 151.70 & 45.50 & \\
F4 (dorsal) & 10.10 & 136.20 & 40.90 & Negative \\
F4 (lateral) & 10.08 & 3.60 & 1.10 & Negative \\
F4 (ventral) & 10.05 & 199.40 & 59.80 & Negative \\
Mean & - & 113.10 & 33.90 & \\
\hline Co c coran & & & & \\
\hline
\end{tabular}

Cco, carbon monoxide content; $\mathrm{U}$, uncertainty. The results obtained from the average of three determinations are expressed in ng/g of carbon monoxide.

Table 2. Carbon monoxide content and uncertainty in tuna loins analyzed in second step (November-December 2013).

\begin{tabular}{lcccc} 
Sample & Sample weight $(\mathrm{g})$ & Cco $(\mathrm{ng} / \mathrm{g})$ & $\mathrm{U}(\mathrm{ng} / \mathrm{g})$ & Result \\
F1 (dorsal) & 10.02 & 92.90 & 27.90 & Negative \\
F1 (lateral) & 10.01 & 16.50 & 4.90 & Negative \\
F1 (ventral) & 10.01 & 133.01 & 39.90 & Negative \\
Mean & & 80.8 & 24.20 & \\
F2 (dorsal) & 10.00 & 289.3 & 86.8 & Positive \\
F2 (lateral) & 10.00 & 142.4 & 42.7 & Negative \\
F2 (ventral) & 10.05 & 254.8 & 76.4 & Negative \\
Mean & & 228.8 & 68.6 & \\
\hline F3 (dorsal) & 10.08 & 115.6 & 34.7 & Negative \\
F3 (lateral) & 10.00 & 208.7 & 62.6 & Negative \\
F3 (ventral) & 10.04 & 71.3 & 21.7 & Negative \\
Mean & & 131.9 & 39.6 & \\
F4 (dorsal) & 10.18 & 243.2 & 73.0 & Negative \\
F4 (lateral) & 10.08 & 305.6 & 91.7 & Positive \\
F4 (ventral) & 10.05 & 302.5 & 90.8 & Positive \\
Mean & & 283.8 & 85.1 & \\
\hline
\end{tabular}

Cco, carbon monoxide content; $\mathrm{U}$, uncertainty. The results obtained from the average of three determinations are expressed in $\mathrm{ng} / \mathrm{g}$ of carbon monoxide.

Japanese government has developed a chromatographic method (GC/FID nickel catalyst) to regulate the import/export of fishery products (Hsieh et al., 1998; Ishiwata et al., 1996). At the National and European level, a confirmatory method is strongly required for a trade harmonization of these products, in most cases imported.

\section{References}

Antonini E, Brunori M, 1971. Hemoglobin and myoglobin in their reactions with ligands Frontiers of biology. North-Holland Publ. Co., Amsterdam, The Netherlands.

Bylkas S, Andersson L, 1997. Microburger biochemistry: extraction and spectral characterization of myoglobin from hamburger. $\mathrm{J}$ Chem Educ 74:426.

Cruza A, López-Rivadulla M, Sáncheza I, Bermejoa AM, 1993. Simultaneous determination of carboxyhemoglobin and total hemoglobin in carbon monoxide-intoxicated patients by use of third-derivative spectrophotometry. Anal Lett 26:1087-97.

European Commission, 1995. European Parliament and Council directive of 20 February 1995 on food additives other than colours and sweeteners, 95/2/EC. In: Official Journal, L 61, 18-03-1995, p. 1.

European Commission, 2002. Regulation of the European Parliament and of the Council of 28 January 2002 laying down the general principles and requirements of food law, establishing the European Food Safety Authority and laying down procedures in matters of food safety, 178/2002/EC. In: Official Journal, L31/1, 01-02-2002.

European Commission, 2008. Regulation of the European Parliament and of the Council of 16 December 2008 on food additives, 1333/2008/EC. In: Official Journal, L 354/16, 31-12-2008.

Ishiwata H, Takeda Y, Kawasaki Y, Yoshida R, Sugita T, Sakamoto S, Yamada T, 1996. Concentration of carbon monoxide in commercial fish flesh and in fish flesh exposed to carbon monoxide gas for colour fixing. $\mathrm{J}$ Food Hyg Soc Jpn 37:83-90.

Hsieh P-P, Chow C-J, Chu Y-J, Chen W-L, 1998. Change in colour and quality of tuna during treatment with carbon monoxide gas. $\mathrm{J}$ Food Drug Anal 6:605-13.

Ministry of Health and Welfare of Japan, 1995. Practice of carbon monoxide inspection in raw fishes. Notice of Einyu no. 10, Eika no. 7. Ministry of Health and Welfare of Japan, Tokyo, Japan.

Sano Y, Hashimoto K, 1958. Studies on the dis- 
coloration in fish meat during freezing storage. I. A spectrophotometric method for the simultaneous determination of ferrous and ferric forms of myoglobin in their mixed solutions. B Jpn Soc Sci Fish 24:519-23.

Schubring R, 2008. Use of "filtered smoke" and carbon monoxide with fish. J
Verbrauch Lebensm 3:31-44.

Smulevich G, Droghetti E, Focardi C, Coletta M, Ciaccio C, Nocentini M, 2007. A rapid spectroscopic method to detect the fraudulent treatment of tuna fish with carbon monoxide. Food Chem 101:1071-7.

Stonek F, Dietrich W, Schneeberger C, Vycudilik W, Tschugguel W, 2004.
Quantitative determination of carbon monoxide in cell culture supernatants by spectrofotometric analysis. J Biochem Biophis Method 58:49-58.

Watts DA, Wolfe SK, Duane W, 1978. Brown fate of [ $4 \mathrm{C}]$ carbon monoxide in cooked or stored ground beef samples. J. Agr Food Chem 26:210-4. 